History. We extended the editorial board and agreed with the BMA to share the profits of the journal with the Thoracic Society, to the considerable benefit of the Society.

One of the pleasures of academic life was to search the old literature for a reference; the smell of dusty volumes, the quiet of the library, and the interest of finding those completely unexpected papers close to the one you were looking for. How much the modern researcher misses by simply sitting at a computer screen. Try looking through old Thorax volumes. You will find the first description of mesothelioma, Richard Doll's first paper (no statistics), results of lung cancer resection not bettered today, the first papers on mesothelioma in erionite exposure, early papers on bronchopulmonary aspergillosis and occupational asthma, and a description of the morning dip in asthma. In 1981 we published a short series of papers to mark the bicentenary of Läennec's birth.

We were pretty strict on the length of papers and I was a ruthless remover of unnecessary words and sentences, but by 1980 we needed to expand to monthly publication. The work was becoming impossible from a full time post so I negotiated a part time salary for my successor, urged on him the need for seeking greater editorial help, and gratefully handed over to Alistair Brewis. It had been a wonderful experience of continuing medical education without the need to fill in forms and satisfy appraisers. Now, next time you are in the library, take this test. Open an early volume at random at three or four pages and then do the same in a recent one. What does that tell you about life? Editor, 1977-1982

Thorax 2006;61:1017-1018.

doi: $10.1136 /$ thx.2006.072330

Correspondence to: Professor A Seaton a.seaton@abdn.ac.uk

\title{
Thorax in the 1980s
}

\section{R A L Brewis}

R eflecting on the experience of editing Thorax, now more than 20 years ago, what stands out in the memory is not any individual ground breaking paper but rather an impression of the huge variety of topics which clamoured for attention under the thoracic banner, and of the general mood of enthusiasm and cooperation which prevailed at the time.

By the early 1980s respiratory medicine had broadened out from its earlier essential focus on tuberculosis and industrial lung disease and seemed at last to have an established position within general medicine. Bright young academic minds were increasingly attracted to the specialty and the quantity and quality of research were advancing in proportion. The British Thoracic Society was newly formed and had confirmed Thorax as its official organ. The general enthusiasm for the subject clearly evident in the Society's meetings was transmitted to the journal. Specialists from a rapidly widening variety of clinical disciplines and basic sciences contributed to the submitted papers, and there was a steady increase in submissions from overseas. Thoracic surgery with its more direct links to cardiology was also changing in character but maintained a strong presence and, up to this time, Thorax still had medical and surgical editors working in tandem. The Editorial Board, which had tended to be the preserve of the silver haired and distinguished, became populated by younger high performers.

The task of editing Thorax was an exciting one involving responsibility, privilege, and a great deal of hard graft-much like doctoring in general. The role had something in common with that of an overworked paediatrician confronted by doting parents (authors) with ailing offspring (papers). In each case a careful history would be followed by detailed examination and, with the help of investigations and specialist advice, the formulation of a diagnosis and then a plan of action directed, wherever possible, towards a successful outcome (publication). In some the course of the illness was protracted; in others radical surgery might be required. Regularly it was necessary to break bad news.

The Editor felt responsible for ensuring fair treatment of authors and an obligation to be true to scientific and ethical principles, but additionally felt a duty to stand as representative of the common reader. This proxy role was assumed to excuse the arrogance of the working rule that, if the editor did not understand something, there was something wrong with the material or the author's presentation. Experience showed that the most impressive researchers were able to describe even advanced concepts in simple terms whereas lesser individuals often tended towards over-elaboration and lack of clarity. One of the most enjoyable aspects of the Editor's role was the licence it gave to approach anyone with special understanding or expertise with a view to producing an illuminating editorial.

An underlying practical challenge was that of improving the actual process of assessing and publishing papers. Opportunities to meet editors from other fields and access to kindly guidance from Stephen Lock were helpful here, as was a steady improvement in the overall standard of work submitted. This was typified by better understanding of the use of statistics, facilitated in the medical field by Douglas Altman and Sheila Gore among others.

Any Editor leans heavily on those who are both highly effective and good natured, and it quickly becomes clear who qualifies under both headings. One of the lessons learnt as Editor was how astonishingly consistent people are. Someone who returns material the next day will continue to be a lightning performer; someone who requires two reminders before replying will always require two reminders. On the theme of reliability it may be interesting to record that, in the days before e-mails and before the Editorial Office had even a word processor let alone a computer, thousands of paper handling actions were completed without loss or significant delay using a manual typewriter, a handwritten ledger system, and the Royal Mail. In those days at least, the mail performed impressively. If a manuscript was held up or thought to be lost, it was invariably located later in some hospital or university post room, or in the office of the author making the enquiry. It is nice to be able to record here the contribution made by Thorax secretaries. Some authors writing in the 1980s will recall the efficiency and alertness of Pat Haselhurst who set a standard happily taken up by the 
secretaries to the newly appointed Associate Editors and maintained, it seems, to the present.

The Associate Editors were the key to the next stage in the growing up of Thorax. Dividing up the workload had become a practical necessity given the volume of time consuming work, but what resulted was teamwork which improved the standard and broadened the character of the journal as well as providing stimulating companionship.

Jumping ahead two decades, we find Thorax promoted to a higher league having emerged from its domestic embrace to be resoundingly adopted by the international respiratory community as a whole. Quality undoubtedly attracts quality, but this virtuous positive feedback is not an automatic process. The combination of energy, imagination, and care contributed by the recent Editors has been the essential catalyst and great credit is due to them. Editing is often described as a thankless task. This may not be strictly true, but it is very nearly so. Few letters of thanks are to be found pinned to the Editor's wall (or, nowadays, perhaps un-erased in the inbox). In celebrating the 60th anniversary of Thorax there is an opportunity to thank the Editors of recent years for their part in the evolution of a journal in which all involved in thoracic medicine and its related sciences can take some pride.

Congratulations Thorax; thank you recent Editors; keep going ...

Editor, 1982-1987

Thorax 2006;61:1018-1019.

doi: $10.1136 /$ thx.2006.072702

Correspondence to: $\operatorname{Dr} R$ A L Brewis, High Barn, High Side, Bassenthwaite, Keswick, Cumbria CA12 4QG; alistairbrewis@btinternet.com

\section{Thorax at 60}

\section{A E Tattersfield}

$\mathrm{E}$ ditors look for articles that say something new, and studies don't have to be large and grand. I have selected two papers and an editorial from among the many I could have chosen. They may not be landmark articles, but they are probably the three articles I have quoted most widely in discussions and teaching. I enjoy the fact that the two studies are simple, showing that valuable information can still be obtained by studying patients carefully and without breaking the bank.

First is a paper by Tweedale et al which looked at short term repeatability of $\mathrm{FEV}_{1}$ and bronchodilator responsiveness in patients with airflow obstruction. The authors showed that within subject differences in $\mathrm{FEV}_{1}$ measurements made 20 minutes apart were usually within $160 \mathrm{ml}$, and that this was true whether the initial FEV 1 was 1 or 5 litres. This has been enormously useful when planning studies and also when interpreting small changes in $\mathrm{FEV}_{1}$ in individual patients. The article also highlighted the difficulty of defining a bronchodilator response-whether to use a percentage change which favours patients with a low $\mathrm{FEV}_{1}$ or an absolute response exceeding $160 \mathrm{ml}$, which favours those with a high $\mathrm{FEV}_{1}$ - to mention just two methods The paper didn't provide the answer but, by relating responses to repeatability, provided a clearer picture of how such data should be interpreted.

Second is an even simpler study, ${ }^{2}$ carried out I think by a medical student, which refuted the classical teaching that detection of cyanosis implies that the patient has $5 \mathrm{~g} / \mathrm{dl}$ reduced haemoglobin. This assertion had been questioned by Flenley among others but was (and still is) repeated by most medical students and some widely used textbooks. In the Thorax paper two observers looked for cyanosis in 80 normothermic patients with a wide range of arterial oxygen tensions. Cyanosis was detected invariably when the reduced haemoglobin concentration approached $1.5 \mathrm{~g} / \mathrm{dl}$, equivalent to an oxygen saturation of around $90 \%$ in patients with a normal haemoglobin concentration. This can be confirmed easily on any ward round Although knowing the correct cut off may be less important now that oximeters are widely available, understanding the physiological basis of clinical signs is important for sensible interpretation and management. A further point is whether students will be penalised if they give the correct answer, since many teachers and presumably examiners still appear to believe that the cut off is $5 \mathrm{~g} / \mathrm{dl}$. If they are, please refer the examiner to this paper.
And finally-the editorial ${ }^{3}$ in which McNeil, Sveger and Thelin discussed the psychosocial effects of neonatal screening for somatic mutations, based on screen-

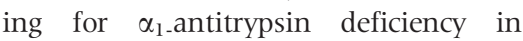
Sweden in the 1970s. It may seem obvious that parents who were told that their child had $\alpha_{1}$-antitrypsin deficiency would take extra precautions to ensure that the child was brought up in a smoke free environment. Not so, however. Follow up studies showed that the stress induced by receiving information about a "potential disease" had the opposite effect, with at least one parent smoking in over half the homes (and twice as many fathers smoked compared with a control group) and the children showed more behavioural problems. The 1970s were early days for understanding the natural history of $\alpha_{1}$-antitrypsin deficiency, for genetic counselling, and for the public's understanding of genetics, and all would be very different today. The message, however, that the effects of counselling need to be tested and cannot necessarily be assumed, is still valid. Editor, 1987-1991

Thorax 2006;61:1019.

doi: $10.1136 /$ thx. 2006.072686

Correspondence to: Professor A E Tattersfield, Division of Respiratory Medicine, Clinical Sciences Building, Nottingham University Hospital, City Hospital Campus, Nottingham NG5 1PB, UK; anne.tattersfield@nottingham. ac.uk

\section{REFERENCES}

1 Tweedale PM, Alexander F, McHardy GJR. Short term variability in $\mathrm{FEV}_{1}$ and bronchodilator responsiveness in patients with obstructive ventilatory defects. Thorax 1987:42:487-90.

2 Goss GA, Hayes JA, Burdon JGW. Deoxyhaemoglobin concentrations in the detection of cyanosis. Thorax 1988;43:212-3.

3 McNeil TF, Sveger T, Thelin T. Psychosocial effects of screening for somatic risk: the Swedish alpha 1 antitrypsin experience. Thorax 1988;43:505-7 